\title{
Helium ion microscopy visualizes lipid nanodomains in mammalian cells
}

Article

Accepted Version

Schürmann, M., Frese, N., Beyer, A., Heimann, P., Widera, D., Mönkemöller, V., Huser, T., Barbara, K., Christian, K. and Armin, G. (2015) Helium ion microscopy visualizes lipid nanodomains in mammalian cells. Small, 11 (43). pp. 57815789. ISSN 1613-6810 doi: https://doi.org/10.1002/smll.201501540 Available at https://centaur.reading.ac.uk/41592/

It is advisable to refer to the publisher's version if you intend to cite from the work. See Guidance on citing.

To link to this article DOI: http://dx.doi.org/10.1002/smll.201501540

Publisher: John Wiley \& Sons

All outputs in CentAUR are protected by Intellectual Property Rights law, including copyright law. Copyright and IPR is retained by the creators or other copyright holders. Terms and conditions for use of this material are defined in the End User Agreement.

www.reading.ac.uk/centaur 
Central Archive at the University of Reading

Reading's research outputs online 


\title{
Helium Ion Microscopy visualizes Lipid Nanodomains in Mammalian Cells
}

\author{
Matthias Schürmann ${ }^{1,}$ *, Natalie Frese ${ }^{2,}$, André Beyer ${ }^{2}$, Peter Heimann $^{1}$, Darius Widera $^{1,3}$, \\ Viola Mönkemöller², Thomas Huser², Barbara Kaltschmidt ${ }^{1}$,

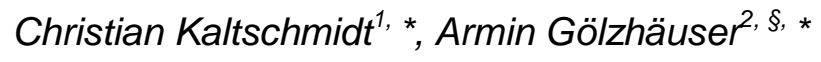 \\ ${ }^{1}$ Faculty of Biology, Bielefeld University, 33501 Bielefeld, Germany \\ ${ }^{2}$ Faculty of Physics, Bielefeld University, 33501 Bielefeld, Germany \\ ${ }^{3}$ Reading School of Pharmacy, University of Reading, Reading, United Kingdom \\ *authors contributed equally \\ §corresponding author: ag@uni-bielefeld.de
}

Keywords: Helium Ion Microscopy, Bioimaging, Lipid Nanodomains, Lipid Rafts, Atomic Force Microscopy 


\begin{abstract}
Cell membranes are composed of two-dimensional bilayers of amphipathic lipids, which allow a lateral movement of the respective membrane components. These components are arranged in an inhomogeneous manner as transient micro- and nanodomains, which are believed to be crucially involved in the regulation of signal transduction pathways in mammalian cells. Because of their small size (diameter 10-200 nm), membrane nanodomains cannot be directly imaged using conventional light microscopy. Here, we present direct visualization of cell membrane nanodomains by helium ion microscopy (HIM). We show that HIM is capable to image biological specimens without any conductive coating, and that HIM images clearly allow the identification of nanodomains in the ultrastructure of membranes with $1.5 \mathrm{~nm}$ resolution. The shape of these nanodomains is preserved by fixation of the surrounding unsaturated fatty acids while saturated fatty acids inside the nanodomains are selectively removed. Atomic force microscopy, fluorescence microscopy, 3D structured illumination microscopy and direct stochastic optical reconstruction microscopy provide additional evidence that the structures in the HIM images of cell membranes originate from membrane nanodomains. The nanodomains observed by HIM have an average diameter of $20 \mathrm{~nm}$ and are densely arranged with a minimal nearest neighbor distance of $\sim 15 \mathrm{~nm}$.
\end{abstract}




\section{Introduction}

According to the classic liquid mosaic model, cell membranes represent a two-dimensional lipid bilayer allowing for free lateral diffusion of membrane components ${ }^{[1]}$. Since its initial postulation, the liquid mosaic model has been substantially modified based on various findings made with regards to inhomogeneities in cell membranes on the micro- and nanoscale ${ }^{[2,3]}$. Such small detergent-resistant membrane nanodomains are called "lipid rafts" and are constituted mostly of sphingolipids with a much higher number of saturated bonds ${ }^{[4]}$ per molecule as compared to other common membrane lipids e.g. phosphatidylcholine ${ }^{[5]}$. A special type of raft-like nanodomains are the so called "caveolae", which are raft-like membrane invaginations stabilized by caveolin ${ }^{[3]}$. Based on their size in the range of 10-200 $\mathrm{nm}^{[6]}$, these membrane domains (lipid rafts and caveolae) can be collectively termed membrane nanodomains ${ }^{[7]}$. Due to their size < $200 \mathrm{~nm}$, membrane nanodomains like lipid rafts $200 \mathrm{~nm}$ cannot be assessed by confocal microscopy. In principle, transmission electron microscopy (TEM) could assess the size of such nanodomains. However, lipid rafts cannot be measured directly, because they cannot be distinguished from the surrounding cell membrane. Thus, mostly indirect methods have been applied to measure their size. Older studies based on the lateral diffusion of glycosylphosphatidylinositol-anchored (GPI-anchored) proteins suggested a size between 200$300 \mathrm{~nm}^{[8,9]}$. However, modern, super-resolution based approaches based on investigation of diffusion GPI-anchored proteins point towards a smaller diameter of approximately $20 \mathrm{~nm}^{[10]}$. Similarly, single particle tracking of GPl-anchored proteins demonstrated a size of $\sim 26 \mathrm{~nm}^{[11]}$. Further, Krager and colleagues used a biotinylated lipid raft reporter for TEM investigation of plasma membrane nano/microdomains and reported cluster sizes of $20-50 \mathrm{~nm}^{[12]}$.

The size and density of membrane nanodomains are believed to play a substantial role in many membrane-related biological processes such as apoptosis ${ }^{[13]}$, endocytosis, exocytosis and immune response $^{[14]}$ as well as in cancer ${ }^{[15]}$. Moreover, membrane nanodomains play an important role in the biology of neurons, as they are involved in neurotransmitter signaling. Changes in neuronal membrane nanodomains may be associated with age-related neurological diseases including Parkinson and Alzheimer ${ }^{[16-19]}$. Due to their nanoscale size below the diffraction limit of conventional light microscopy, membrane nanodomains have been mostly studied by indirect biophysical methods (reviewed in ref. ${ }^{[20]}$ and ${ }^{[21]}$ ). Hell and coworkers utilized stimulated emission depletion (STED) microscopy to tune the optical resolution of a confocal laser beam from $250 \mathrm{~nm}$ down to $20 \mathrm{~nm}$ to directly monitor the diffusion and formation dynamics of membrane lipids in a living cell[10]. In an extended approach, the same group applied coaligned dual-channel STED to quantify the diffusion of labeled lipids in cell membranes with a 
spatial resolution down to $20 \mathrm{~nm}^{[22]}$. Despite STED's ability to image fast dynamic processes, a direct spatial imaging of these structures in living cells has not yet been accomplished. The extended spatial resolution of super resolution optical microscopy is well complemented by combination with modern electron microscopy. During the last decades Scanning Electron Microscopy (SEM) has become a widespread instrument to investigate the surface structure of biological samples with a resolution between 2-5 $\mathrm{nm}^{[23]}$. However, since imaging by SEM inevitably introduces electric charge into the specimen it is necessary to render the sample conductive, which is routinely accomplished by coating the sample with a thin metal film. The drawback of this technique is that the metal coating might obscure small structural features.

Since the 2010's helium ion microscopes (HIM) are commercially available. In a HIM, a focused beam of positive helium ions $\left(\mathrm{He}^{+}\right)$is utilized to scan a sample surface, leading to the ejection of secondary electrons (SE) that are then detected ${ }^{[24]}$. Like in a scanning electron microscope, the local variation of the SE intensity is converted into a greyscale image. Soon after its introduction, the HIM evolved into a very useful tool in materials science. Its small $\mathrm{He}^{+}$beam can be focused with a diameter below $0.3 \mathrm{~nm}$, which leads to high-resolution images. In addition, a pronounced material contrast is generated due to a high variation of elemental cross-sections of $\mathrm{He}^{+}$ions, leading to additional information for chemically heterogeneous samples (a recent review on HIM is found in ref. ${ }^{[25]}$ ). A HIM can also provide sharp images from electrically insulating samples. This is achieved by a charge compensation, in which positive charges deposited by the $\mathrm{He}^{+}$ beam are neutralized by an electron beam thus balancing the charge of the incoming $\mathrm{He}^{+}$ions and the outgoing secondary electrons. Armed with this capability, the HIM successfully imaged complex biological specimen such as Arabidopsis thaliana sepal cuticle or the human cell line HeLa during mitosis with sub-nanometer resolution ${ }^{[26]}$. Using HIM and its charge compensation, networks of collagen fibers in cartilage ${ }^{[23]}$ and polymerized fibrin fibers in a $3 D$ matrix used for stem cell cultivation ${ }^{[27]}$ were visualized. Thus, the HIM is an ideal tool to explore the nanostructural details of biological membranes and membrane nanodomains.

Here, we investigate the ultrastructure of cell membranes with the helium ion microscope. We found that all mammalian cell types studied exhibit pit-like features with average diameters of 20 $\mathrm{nm}$. We provide evidence that these pit-like membrane inhomogeneities represent membrane nanodomains within an ordered liquid phase. Moreover, our data suggest that these membrane nanodomains are lipid-raft-like domains and caveolae visualized using HIM with a resolution of $1.5 \mathrm{~nm}$.

\section{Results and Discussion}


Because of their small size, well below the optical resolution limit, nanoscale membrane inhomogeneities cannot be assessed by conventional light microscopy. However, such nanodomains seem to play an important role in health and disease ${ }^{[18,19]}$, making the study of their structure and composition particularly important. We have imaged cultured, undifferentiated adult human neural crest-derived stem cells (NCSCs) from the human respiratory mucosa ${ }^{[28]}$ and NCSC-derived human neurons ${ }^{[29]}$ with a helium ion microscope. Figure 1 A-C shows images of NCSC-derived human neurons with and figure $1 D-F$ without an initial gold coating.

In both approaches, stem cells differentiated into neurons showed a round and defined cell body and numerous slender, branching and long projections with small diameters representing neurites (Fig. 1 A, D). Remarkably, in specimens sputter-coated with gold (Au) with a typical thickness of approx. $10 \mathrm{~nm}$ (Fig. $1 \mathrm{~A}-\mathrm{C}$ ), the cell membrane is covered with clustered $\mathrm{Au}$, masking the cell surface. The evaluation of HIM images of uncoated, native-state cell membranes revealed numerous pit-like membrane inhomogeneities or domains with varying diameters that are rarely visible in coated cells (Fig. 1 D-F). This becomes particularly clear by comparing the high magnification HIM images in Fig. $1 \mathrm{C}$ and Fig. $1 F$, which show regions on the somata of the cells. We also performed HIM imaging on the neurites of stem cells differentiated into neurons, cf. Supplementary Fig 1. To verify the three-dimensional appearance of the inhomogeneities, further HIM imaging of uncoated specimens was performed, cf. figure 2 and Supplementary Fig. 2.

Human neurons are of limited availability and accessibility. Very recently, we successfully differentiated adult human neural crest-derived stem cells into neurons with forebrain and midbrain characteristics ${ }^{[29]}$. Therefore here we employed human stem cell-derived neurons as a model system to study human neuronal cells. Additionally to these cells, we used different cell types for HIM imaging to exclude inter-species variations and potential impact of the differentiation method (Fig. 2).

Adult human NCSCs were imaged either undifferentiated (Fig. 2 A), or differentiated into neurons (Fig. 2 B), which showed typical shape and diverse neurites closely resembling morphological features of primary neurons from embryonic mouse hippocampus cultured for 4 days (Fig. 2 C). Importantly, the cell surfaces of all three cell types (NCSCs, differentiated NCSCs and primary neurons) showed anisotropically distributed pit-like structures (Fig. 2 D, E, F). 
It is our hypothesis that the pit-like domains are a direct visualization of the shape of membrane nanodomains, including lipid rafts and caveolae. These nanodomains consist mainly of saturated fatty acids while the lipid bilayer outside of the nanodomains consists of unsaturated fatty acids. It is known, that osmium tetroxide $\left(\mathrm{OsO}_{4}\right)$ used in the cell fixation and drying (see methods) reacts with unsaturated fatty acids inside the lipid membrane to create cyclic ethers ${ }^{[30]}$. If two unsaturated fatty acids are positioned in the right manner this is followed by a cross linking of the membrane. On the other hand, saturated fatty acids in lipid membranes do not crosslink with $\mathrm{OsO}_{4}$ as shown below. Thus, we conclude that the cell fixation with $\mathrm{OsO}_{4}$ crosslinks the lipid bilayer outside the nanodomains while the lipid bilayer inside the nanodomains is removed by the required subsequent rinsing with ethanol for the cell drying process. Therefore, imaging with HIM reveals the shape of the nanodomains as missing lipid bilayer domains, i.e. pit-like structures. In addition, we performed freeze drying of stem cells differentiated into neurons after fixation with aldehydes and $\mathrm{OsO}_{4}$. HIM imaging of these cells also shows nanodomains in the cell membranes, cf. Supplementary Fig. 3. It follows that the nanodomains are not only unstable in ethanol but also in air.

Support of our hypothesis was obtained by reproducing the proposed mechanism of selective cross-linking and ethanol based removal with a lipid bilayer model-system. For this purpose we generated supported lipid bilayers (SLBs) composed of a 1:1 mixture of 1,2-dioleoyl-sn-glycerol3-phosphocholine (DOPC) and 1,2-Distearoyl-sn-glycerol-3-phosphocholine (DSPC) on a Mica surface (Fig. 3). Such SLBs are widely used as models to investigate phospholipid membranes mimicking biological surfaces including cell membranes and can be accessed by $A F M^{[31]}$. Remarkably, the DOPC and DSPC lipid domains can be distinguished based on their height difference relative to the mica surface ${ }^{[32]}$.

The separation of the two phases in the bilayer into a gel-like DSPC and more fluid DOPC domains is apparent as a height difference of about $1.5 \mathrm{~nm}$ (Fig. 3 C). Here, DSPC lipid domains (bright areas, $\sim 7 \mathrm{~nm}$ ) can be clearly differentiated from DOPC domains (dark areas, $5.5 \mathrm{~nm}$ ). After treatment with $\mathrm{OsO}_{4}$ and subsequent $\mathrm{EtOH}$ extraction of lipids, ethanol extraction resistant DOPC domains remain detectable by their height and shape using AFM (Fig. 3 D). Importantly, $D O P C$ domains in the bilayer cross-linked by the $\mathrm{OsO}_{4}$ treatment are able to withstand the extraction process with ethanol, which clearly proves the effectiveness of the proposed mechanism of a spatially selective cross-linking and ethanol-based removal.

Further visualization of the proposed mechanism was obtained with mammalian cells by fluorescence-based imaging techniques. Therefore, we stained fixed NCSCs using aldehydes 
and $\mathrm{OsO}_{4}$ followed by labeling of lipid domains using Alexa Fluor 488 - coupled to cholera toxin fragment $B$ (CTXB) (Fig. 5). CTXB is known to efficiently label a fraction of raft-like lipid nanodomains in cells by binding to Gangliosid $1^{[6,33,34]}$.

Fig. 4 shows that domains of the cell membrane positive for CTXB can get extracted with $70 \%$ ethanol as visualized by a loss of the corresponding fluorescence signal only in the EtOH-treated specimen (Fig. 4 B) in comparison to the control sample, which was prepared in the same way except for the EtOH-treatment (Fig. 4 A). The visualized extraction of CTxB-labelled membrane domains indicates that our proposed mechanism of selective cross-linking and EtOH-based removal is not only effective in model membranes but also detectable in membranes of mammalian cells. Thus, we can infer that the pit-like membrane domains in the HIM images visualize the shape of lipid raft-like domains and/or caveolae.

Higher resolved fluorescence images reveal the distribution of the CTXB labels in the samples without EtOH-treatment by 3D structured illumination microscopy (3D-SIM) and direct stochastic optical reconstruction microscopy (dSTORM), cf. Fig. $4 C$ and D, respectively. These images show that the CTXB labels are arranged in the form of nanodomains and are co-localized with actin which proves that the raft-like lipid nanodomains are present in the investigated mammalian cells ${ }^{[35]}$.

Concluding from dSTORM that the nanodomains visualized in HIM are also visible with an independent method, we used the superior resolution of HIM to quantify lipid nanodomains. We therefore measured the diameters and mean nearest neighbor distances of pit-like structures (lipid nanodomains) in three different cell types: NCSCs, neuronally differentiated stem cells and mouse hippocampal neurons.

For all three cell types we measured a mean diameter $\leq 20 \mathrm{~nm}$ suggesting that most of pitstructures are raft-like (Fig. 6 B). This is in general accordance with the consensus size definition of lipid rafts, claiming raft diameters of $10-200 \mathrm{~nm}^{[6]}$.

Due to the overlapping size of lipid raft-like membrane nanodomains (diameter of lipid rafts: 10$200 \mathrm{~nm}^{[6,36-38]}$; diameter of caveolae: $50-120 \mathrm{~nm}$ with an open pore of 30-50 $\mathrm{nm}^{[39,40]}$ ) the measurement of the pit-diameter is not sufficient to distinguish between both nanodomains. Thus, in addition to the determination of the diameter (Fig. $5 \mathrm{~A}$ ) we measured the mean distance between the respective neighboring nanodomains in NCSCs, stem cell-derived human neurons and mouse hippocampal neurons. Caveolae are invaginations of the cell membrane, which look in a section like a balloon cf. Supplementary Fig. 6. Since the diameter of the caveolae is in the 
range of 50-120 nm it is impossible that the openings of two caveolae can lie closer to each other than $50 \mathrm{~nm}$. Hence we conclude that the fraction of the pit-like structures revealed by HIM having distances to the neighboring domain $<50 \mathrm{~nm}$ represent at least partly lipid-raft like membrane nanodomains and not caveolae (Fig. 5 C).

In summary, we present a strong line of evidence that pit-like structures revealed in helium ion microscopy images of mammalian cell membranes represent both lipid raft-like membrane nanodomains and caveolae. Since its first introduction, the concept of lipid rafts is still controversial and a matter of ongoing scientific debate ${ }^{[4,}{ }^{41]}$. However, cholesterol and sphingolipid-rich microdomains within the cell membrane seem to have tremendous impact on elementary functions of different cell types including signal transduction and regulation of the cell fate. The controversy of the lipid raft concept is partly driven by fact that they are difficult to visualize in cells. Our study allows for the first time a direct observation of lipid raft-like nanodomains that appear as pit-like structures in unstained and uncoated cell membrane. Thus, broad application of HIM in lipid raft research could crucially contribute to clarification of open questions on their size and (sub-) cellular distribution in different cell types. As helium ion microscopy is a versatile and "easy to use" method, it is expected to find numerous applications in biological and medical research, opening new opportunities for bioimaging with ions, especially if correlated with other state-of-the-art methods, such as super-resolution optical microscopy, cryo-electron microscopy, or nano-mass spectrometry, thus pushing the limits in soft-matter research. 


\section{Material and Methods}

\section{Cell culture}

Human inferior turbinates were obtained by biopsy during routine surgery after an informed consent according to local (Bezirksregierung Detmold/Münster) and international guidelines. Cell isolation and cultivation was performed as described in ref. ${ }^{[28]}$. Briefly, inferior turbinates were mechanically and enzymatically dissociated and further cultivated in a serum-free medium (DMEM/F12 containing B27 supplement, FGF-2 and EGF). For rapid expansion ITSCs were cultivated in medium supplemented with $10 \%$ human blood plasma as described in ref. ${ }^{[27] .}$ Mouse hippocampal neurons were isolated and cultivated as described in ref. ${ }^{[42]}$. In particular, mouse hippocampal neurons were obtained by dissecting the hippocampi from mouse embryonic stage E17.5 followed by digestion in trypsin EDTA (PAA) for 30 min at $37^{\circ} \mathrm{C}$. Subsequently the tissue was mechanically dissociated by pipetting the solution through a Pasteur pipette. Afterwards the cells were seeded on PEI coated cover slips in DMEM containing $10 \%$ FCS with a density of 1000 cells $/ \mathrm{mm}^{2}$. The medium was changed to neurobasal medium containing 1\% B27 $1 \mathrm{~h}$ and $24 \mathrm{~h}$ after seeding.

\section{Neuronal differentiation of human neural crest stem cells}

Adult human NCSCs were differentiated towards neuronal lineage as described in ref. ${ }^{[29]}$.

\section{HIM imaging}

The samples were imaged with the helium ion microscope ORION PLUS from Zeiss with an accelerating voltage between $35 \mathrm{eV}$ and $40 \mathrm{eV}$ and a beam current between $0.4 \mathrm{pA}$ and $1.1 \mathrm{pA}$. The electron flood gun was used to compensate charging of uncoated samples. For visualization with HIM the cells were fixed with $100 \mathrm{mM}$ sodium cacodylate ( $\mathrm{pH} \mathrm{7.2)} \mathrm{containing} \mathrm{4 \%} \mathrm{PFA} \mathrm{and}$ $4 \%$ glutaraldehyde for $1 \mathrm{~h}$ at $4^{\circ} \mathrm{C}$ followed by lipid fixation in $100 \mathrm{mM}$ sodium cacodylate buffer containing $1.5 \% \mathrm{OsO}_{4}$ for $30 \mathrm{~min}$ at $4{ }^{\circ} \mathrm{C}$. Fixed cells were then dehydrated in ethanol series and critical point dried via $\mathrm{CO}_{2}$ of highest purity. The cover slips were either left in their native state or were sputtered with $10 \mathrm{~nm}$ of gold. Other specimens were freeze dried. For this purpose fixed specimens were washed in distilled water, which was sucked away resulting in a very thin film of water. Subsequently specimens were plunge frozen in liquefied propane at $-190^{\circ} \mathrm{Celsius.} \mathrm{Shock}$ frozen specimens were then transferred under $\mathrm{N}_{2}$-atmosphere into a self-made freeze-drying 
apparatus (consisting in principle out of 2 heavy polished copper blocks having a distance of 5 $\mathrm{mm})$ at $-196^{\circ}$ Celsius. The device was brought into a high-vacuum chamber and dried for 15 hours at $10^{-5}$ millibar. The resolution of the HIM was determined as the distance between two points on a keen edge on which the signal corresponds from $25 \%$ to $75 \%$ of the absolute signal of the edge. For this purpose the signal of ten scan lines which cross an extracted lipid domain were analyzed. The diameters of the pit-like features were determined by calculating equivalent circle areas from the pit-like feature areas which are exemplary red marked in Fig. 5 A. For this purpose, we created a mask by marking the nanodomains with the "mask editor" in Gwyddion and calculated equivalent disc areas by using the "grain functions" in Gwyddion. Furthermore the distances between the middle of every pit-like feature and their next neighboring feature were measured.

\section{Transmission Electron Microscopy}

Animals were transcardially perfused (with a permit of the local authorities) under deep anaesthesia first for $40 \mathrm{sec}$ with heparin/procaine (blood isotonic) followed by $2 \%$ formaldehyde / 4\% glutaraldehyde fixative in $0.1 \mathrm{M}$ phosphate buffer for $10 \mathrm{~min}$. Dissected organs were further fixed for 2-4 hours at $4^{\circ}$ Celsius and postfixed with $2 \%$ OsO4 plus $0.15 \%$ potassium hexacyanoferrate(III) in buffer and embedded in Araldite. Ultrathin sections (70 nm) were contrasted with uranyl acetate and lead citrate and viewed under a Zeiss EM109 electron microscope at $50 \mathrm{kV}$.

\section{Liposome preparation}

Liposomes (1,2-Distearoyl-sn-glycerol-3-phosphocholine (DSPC; 18:0), 1,2-dioleoyl-sn-glycerol3-phosphocholine (DOPC; 18:1), Sigma-Aldrich) were prepared by dissolving the two lipids in chloroform to obtain solutions at a 1:1 ratio. The solvent was removed by drying the mixture in a glass test tube under a nitrogen stream. Re-hydration of the lipid film was accomplished in vesicle buffer consisting of $10 \mathrm{mM}$ HEPES, $150 \mathrm{mM} \mathrm{NaCl}$ and $4 \mathrm{mM} \mathrm{CaCl}_{2}$ at $\mathrm{pH} 7.4$ obtaining a dispersion with an overall lipid concentration of $1 \mathrm{mM}$. Small unilamellar vesicles (SUV) were formed by sonication in a water bath of an ultrasonic cleaner which was heated to approximately $60^{\circ} \mathrm{C}$ slightly above the transition temperature of DSPC $\left(55^{\circ} \mathrm{C}\right)$ until the dispersion became only slightly hazy. To remove the lipid debris generated during the SUV formation the dispersion was centrifuged for $3 \mathrm{~min}$ at $2000 \mathrm{~g}$.

\section{Supported lipid bilayer formation}


The supported planar bilayer was formed by incubation of freshly cleaved mica with the SUV dispersion for 30 min at RT. Subsequently the mica was washed three times with vesicle buffer. Following this primary washing steps the mica was further washed to remove excess liposomes and calcium prior to AFM imaging using rinsing buffer composed of $10 \mathrm{mM}$ HEPES, $150 \mathrm{mM}$ $\mathrm{NaCl}$ and $4 \mathrm{mM}$ EDTA at a $\mathrm{pH}$ of 7.4 .

\section{AFM imaging and fixation of the supported planar bilayer}

AFM imaging was performed using the NT-MDT Ntegra device in tapping mode at RT in rinsing buffer as described above (Supported Lipid bilayer formation). The image acquisition was performed using a piezo scanner with a maximum scanning area of $71.3 \mu \mathrm{m}$ and a $225 \mu \mathrm{m}$ long $V$-shaped cantilever with a spring constant of approximately $0.03 \mathrm{~N} / \mathrm{m}$. The AFM images were acquired with a scan rate of $0.3 \mathrm{~Hz}$ and a tip oscillating frequency of $12.2 \mathrm{kHz}$. Fixation of the supported planar lipid bilayer was performed by submerging the bilayer in $100 \mathrm{mM}$ sodium cacodylate buffer containing $1.5 \% \mathrm{OsO}_{4}$ for 30 min at RT. Extraction of the unfixed lipid with ethanol was executed by rinsing the bilayer with $70 \%$ ethanol for three times.

\section{CTxB staining and confocal fluorescence imaging}

For staining with Cholera Toxin subunit B ITSCs were plated on glass cover slips in DMEM containing 10\% FCS and fixed as described above (HIM imaging). Subsequently the cells were either washed with PBS or washed with $70 \%$ ethanol followed by rinsing with PBS. Afterwards the cells were stained with $1 \mu \mathrm{g} / \mathrm{ml} C T \times B$ Alexa Fluor 488 conjugate (life technologies) and 1 $\mu \mathrm{g} / \mathrm{ml}$ DAPI in PBS for $10 \mathrm{~min}$ at RT. To visualize the fluorochromes confocal microscopy was applied (CLSM 780, Carl Zeiss).

\section{Super resolution imaging of lipid rafts}

3D-SIM images of NCSC cells were acquired using a commercial three-dimensional structured illumination microscope (3D-SIM, DeltaVision/OMXv4.0 BLAZE, GE Healthcare, Amersham, UK). To achieve even higher spatial resolution of lipid rafts we used 3D-SIM in combination with single molecule localization microscopy of conventional fluorophores (direct Stochastic Optical Reconstruction Microscopy - dSTORM) on the same setup by changing the illumination mode from structured illumination to ring-TIRF (total internal reflection fluorescence excitation), albeit at an angle just below the critical angle to obtain a highly inclined laminated optical sheet (HiLo) illumination mode. 
To enable their controlled blinking, the CTB-AlexaFluor647 molecules were excited with a 642 $\mathrm{nm}$ laser. The $642 \mathrm{~nm}$ laser power was set to $100 \%$ of laser power so that the density of the blinking fluorophores appears as high as possible while still creating sufficient spatial separation between molecules for single molecule localization. Typical excitation laser power densities were approximately $0.5 \mathrm{~kW} / \mathrm{cm}^{2}$. The acquisition time was $30 \mathrm{~ms}$ per frame and 12,000 frames were recorded using a sCMOS camera (total acquisition time $\sim 10 \mathrm{~min}$ ). Raw data were preprocessed to reduce background signal and single pixel characteristics intrinsic to SCMOS cameras by subtracting the average of the image stack from each individual frame.

For the final reconstruction of a dSTORM image the 12,000 frames were analyzed by the open source reconstruction software rapidSTORM ${ }^{[43]}$. Images were corrected for sample drift by assuming linear drift using the built-in drift correction of rapidSTORM and the localization precision was calculated for each detected fluorophore in rapidSTORM.

dSTORM images were analyzed to extract feature size using Fiji. Thresholding was done using the auto threshold function 'moments'. To extract the size distribution of lipid rafts, Fiji's particle analysis procedure was used with a minimum size of $200 \mathrm{~nm}^{2}$ and a minimum circularity of 0.3 .

\section{Acknowledgements}

We thank $H$. Vieker and B. Völkel for technical help and valuable discussion. We also thank the Volkswagenstiftung for financial support. 


\section{References}

[1] Singer, S. J.; Nicolson, G. L., Science 1972, 175 (4023), 720-31.

[2] Karnovsky, M. J.; Kleinfeld, A. M.; Hoover, R. L.; Klausner, R. D., J Cell Biol 1982, 94 (1), 1-6.

[3] Parton, R. G.; Simons, K., Science 1995, 269 (5229), 1398-9.

[4] Simons, K.; Sampaio, J. L., Cold Spring Harb Perspect Biol 2011, 3 (10), a004697.

[5] Simons, K.; Ikonen, E., Nature 1997, 387 (6633), 569-72.

[6] Pike, L. J., J Lipid Res 2009, 50 Suppl, S323-8.

[7] Horejsi, V.; Hrdinka, M., FEBS Lett 2014, 588 (15), 2392-7.

[8] Jacobson, K.; Sheets, E. D.; Simson, R., Science 1995, 268 (5216), 1441-2.

[9] Sheets, E. D.; Lee, G. M.; Simson, R.; Jacobson, K., Biochemistry 1997, 36 (41), 1244958.

[10] Eggeling, C.; Ringemann, C.; Medda, R.; Schwarzmann, G.; Sandhoff, K.; Polyakova, S.; Belov, V. N.; Hein, B.; von Middendorff, C.; Schonle, A.; Hell, S. W., Nature 2009, 457 (7233), 1159-62.

[11] Pralle, A.; Keller, P.; Florin, E. L.; Simons, K.; Horber, J. K. H., J. Cell. Biol. 2000, 148 (5), 997-1007.

[12] Krager, K. J.; Sarkar, M.; Twait, E. C.; Lill, N. L.; Koland, J. G., J Lipid Res 2012, 53 (10), 2214-25.

[13] George, K. S.; Wu, S., Toxicol Appl Pharmacol 2012, 259 (3), 311-9.

[14] Simons, K.; Gerl, M. J., Nat Rev Mol Cell Biol 2010, 11 (10), 688-99.

[15] Staubach, S.; Hanisch, F. G., Expert Rev Proteomics 2011, 8 (2), 263-77.

[16] Hashimoto, M.; Takenouchi, T.; Rockenstein, E.; Masliah, E., J Neurochem 2003, 85 (6), 1468-79.

[17] Ehehalt, R.; Keller, P.; Haass, C.; Thiele, C.; Simons, K., J Cell Biol 2003, 160 (1), 11323.

[18] Sebastiao, A. M.; Colino-Oliveira, M.; Assaife-Lopes, N.; Dias, R. B.; Ribeiro, J. A., Neuropharmacology 2013, 64, 97-107.

[19] Marin, R.; Rojo, J. A.; Fabelo, N.; Fernandez, C. E.; Diaz, M., Neuroscience 2013, 245, 26-39.

[20] Simons, K.; Toomre, D., Nat Rev Mol Cell Biol 2000, 1 (1), 31-9.

[21] Sonnino, S.; Prinetti, A., Curr Med Chem 2013, 20 (1), 4-21.

[22] Gottfert, F.; Wurm, C. A.; Mueller, V.; Berning, S.; Cordes, V. C.; Honigmann, A.; Hell, S. W., Biophys J 2013, 105 (1), L01-3.

[23] Vanden Berg-Foels, W. S.; Scipioni, L.; Huynh, C.; Wen, X., J Microsc 2012, 246 (2), 168-76.

[24] Ward, B. W.; Notte, J. A.; Economou, N. P., J Vac Sci Technol B 2006, 24 (2871).

[25] Hlavacek, G.; Veligura, V.; van Gastel, R.; Poelsema, J., J. Vac. Sci. Technol. B 2014, 32, 020801.

[26] Joens, M. S.; Huynh, C.; Kasuboski, J. M.; Ferranti, D.; Sigal, Y. J.; Zeitvogel, F.; Obst, M.; Burkhardt, C. J.; Curran, K. P.; Chalasani, S. H.; Stern, L. A.; Goetze, B.; Fitzpatrick, J. A., Sci Rep 2013, 3, 3514.

[27] Greiner, J. F.; Hauser, S.; Widera, D.; Müller, J.; Qunneis, F.; Zander, C.; Martin, I.; Mallah, J.; Schuetzmann, D.; Prante, C.; Schwarze, H.; Prohaska, W.; Beyer, A.; Rott, K.; 
Hütten, A.; Gölzhäuser, A.; Sudhoff, H.; Kaltschmidt, C.; Kaltschmidt, B., Eur Cell Mater 2011, 22, 403-19.

[28] Hauser, S.; Widera, D.; Qunneis, F.; Müller, J.; Zander, C.; Greiner, J.; Strauss, C.; Luningschror, P.; Heimann, P.; Schwarze, H.; Ebmeyer, J.; Sudhoff, H.; Arauzo-Bravo, M. J.; Greber, B.; Zaehres, H.; Scholer, H.; Kaltschmidt, C.; Kaltschmidt, B., Stem Cells Dev 2012, 21 (5), 742-56.

[29] Müller, J.; Ossig, C.; Greiner, J. F.; Hauser, S.; Fauser, M.; Widera, D.; Kaltschmidt, C.; Storch, A.; Kaltschmidt, B., Stem Cells Transl Med 2015, 4 (1), 31-43.

[30] Lang, G., Praxislehrbuch für die Biomedizinische Analytik. In Praxislehrbuch für die Biomedizinische Analytik, Springer: 2013; $p 53$.

[31] Redondo-Morata, L.; Giannotti, M. I.; Sanz, F., Mol Membr Biol 2014, 31 (1), 17-28.

[32] Giocondi, M. C.; Yamamoto, D.; Lesniewska, E.; Milhiet, P. E.; Ando, T.; Le Grimellec, C., Biochim Biophys Acta 2010, 1798 (4), 703-18.

[33] Badizadegan, K.; Wolf, A. A.; Rodighiero, C.; Jobling, M.; Hirst, T. R.; Holmes, R. K.; Lencer, W. I., Int J Med Microbiol 2000, 290 (4-5), 403-8.

[34] Nichols, B. J.; Kenworthy, A. K.; Polishchuk, R. S.; Lodge, R.; Roberts, T. H.; Hirschberg, K.; Phair, R. D.; Lippincott-Schwartz, J., J Cell Biol 2001, 153 (3), 529-41.

[35] Raghupathy, R.; Anilkumar, A. A.; Polley, A.; Singh, P. P.; Yadav, M.; Johnson, C.; Suryawanshi, S.; Saikam, V.; Sawant, S. D.; Panda, A.; Guo, Z.; Vishwakarma, R. A.; Rao, M.; Mayor, S., Cell 2015, 161 (3), 581-94.

[36] Helms, J. B.; Zurzolo, C., Traffic 2004, 5 (4), 247-54.

[37] Rajendran, L.; Simons, K., J Cell Sci 2005, 118 (Pt 6), 1099-102.

[38] Nicolau, D. V., Jr.; Burrage, K.; Parton, R. G.; Hancock, J. F., Mol Cell Biol 2006, 26 (1), 313-23.

[39] Westermann, M.; Leutbecher, H.; Meyer, H. W., Histochem Cell Biol 1999, 111 (1), 71 81.

[40] Cohen, A. W.; Hnasko, R.; Schubert, W.; Lisanti, M. P., Physiol Rev 2004, 84 (4), 1341 79.

[41] Munro, S., Cell 2003, 115 (4), 377-88.

[42] Klenke, C.; Widera, D.; Engelen, T.; Muller, J.; Noll, T.; Niehaus, K.; Schmitz, M. L.; Kaltschmidt, B.; Kaltschmidt, C., PLoS One 2013, 8 (6), e65280.

[43] Wolter, S.; Endesfelder, U.; van de Linde, S.; Heilemann, M.; Sauer, M., Opt Express 2011, 19 (8), 7020-33. 
Figures and Figure legends

\section{Figure 1}

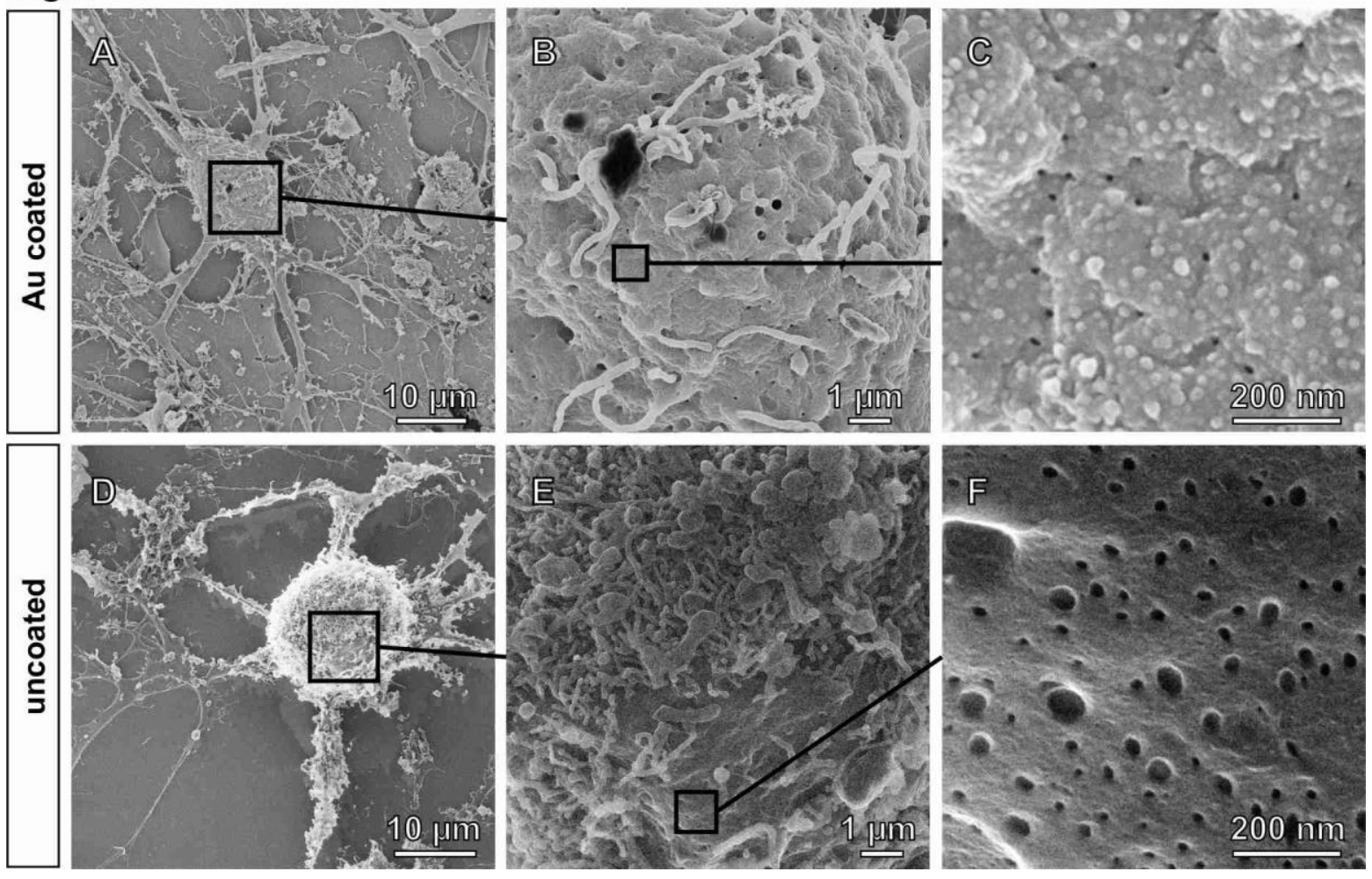

Fig. 1. Helium ion microscopic image of critical point dried stem cells differentiated to the neuronal lineage with and without gold coating. (A, D) Human neural crest-derived stem cells differentiated to neurons with a round and defined cell body and numerous thin, slender, branching and long projections with small diameter representing neurites. (B, E) Cell membrane of soma. (C) In specimens sputter coated with gold ( $\mathrm{Au}$ ) with standard thickness of approx. 10 $\mathrm{nm}$ the cell membrane is covered with clustered Au, masking the true cell surface. (F) Helium ion microscopy allows high resolution inspection of uncoated cell surface in the native state. Numerous nano-domains with a roundish circumference and of varying diameter become discernible. 
Figure 2

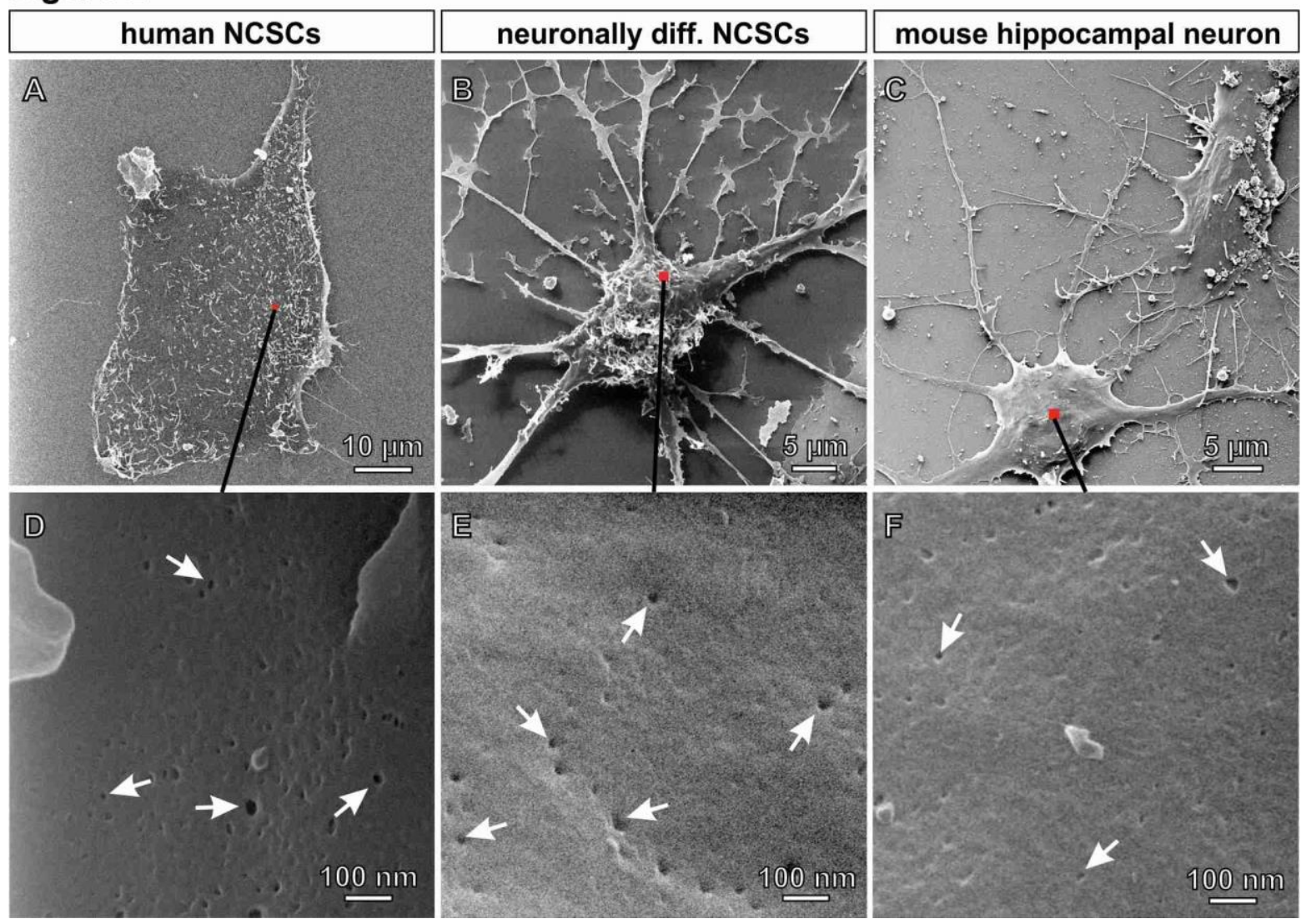

Fig. 2. Pits in ultrastructure of membrane topology are present in different cell types derived from different species. HIM imaging was performed on critical point dried uncoated primary mouse hippocampal mouse neurons (4 days cultured), human NCSCs and human NCSC-derived neurons. (A-C) In the overview all cell types show their typical morphology i.e. undifferentiated, adherent for NCSC (A) and neuronal for primary mouse hippocampal neurons (C) and neuronally differentiated human NCSC (B). Remarkably all images of the different cell membranes acquired at a high magnification (D-F) showed unevenly distributed pit-like structures (arrows). 
Figure 3
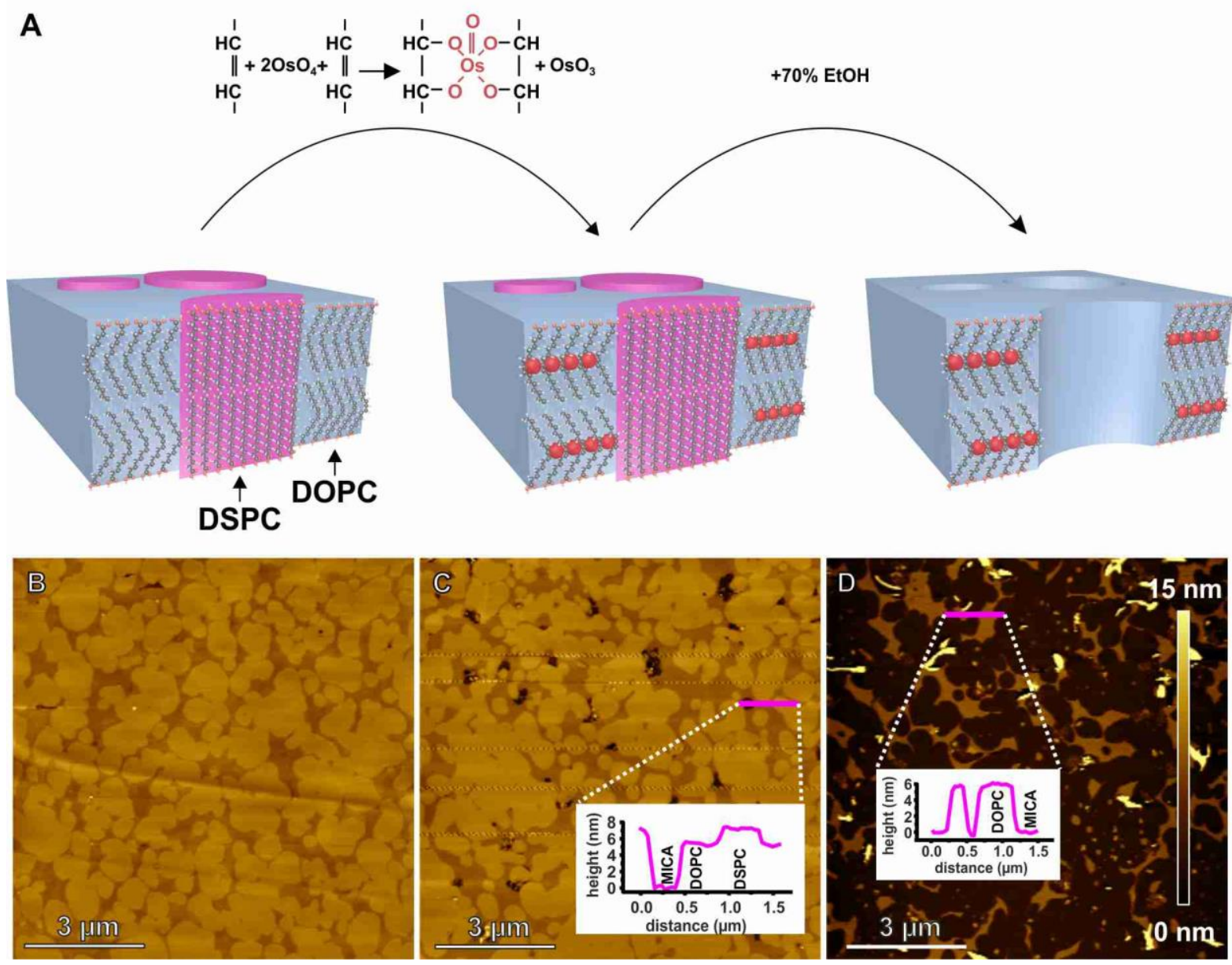

Fig. 3. A proposed mechanism for the generation of pit-like membrane features in a synthetic model membrane. (A) Scheme of the pit formation including the crosslinking of the unsaturated fatty acids via $\mathrm{OsO}_{4}$ and the extraction of the lipid domains by ethanol. (B-D) The experimental test of the hypothesized mechanism with a topographic AFM image of a synthetic lipid membrane. The artificial lipid bilayer showed a characteristic phase separation of the two lipids resulting in domains with a height of $5,5 \mathrm{~nm}$ for DOPC and $7 \mathrm{~nm}$ for DSPC. These height values were measured in respect to the mica substrate, cf. line profile (inset, C). The extraction of the saturated fatty acids domains with ethanol can be easily ascertained by their characteristic shape and height (inset, D). 
Figure 4

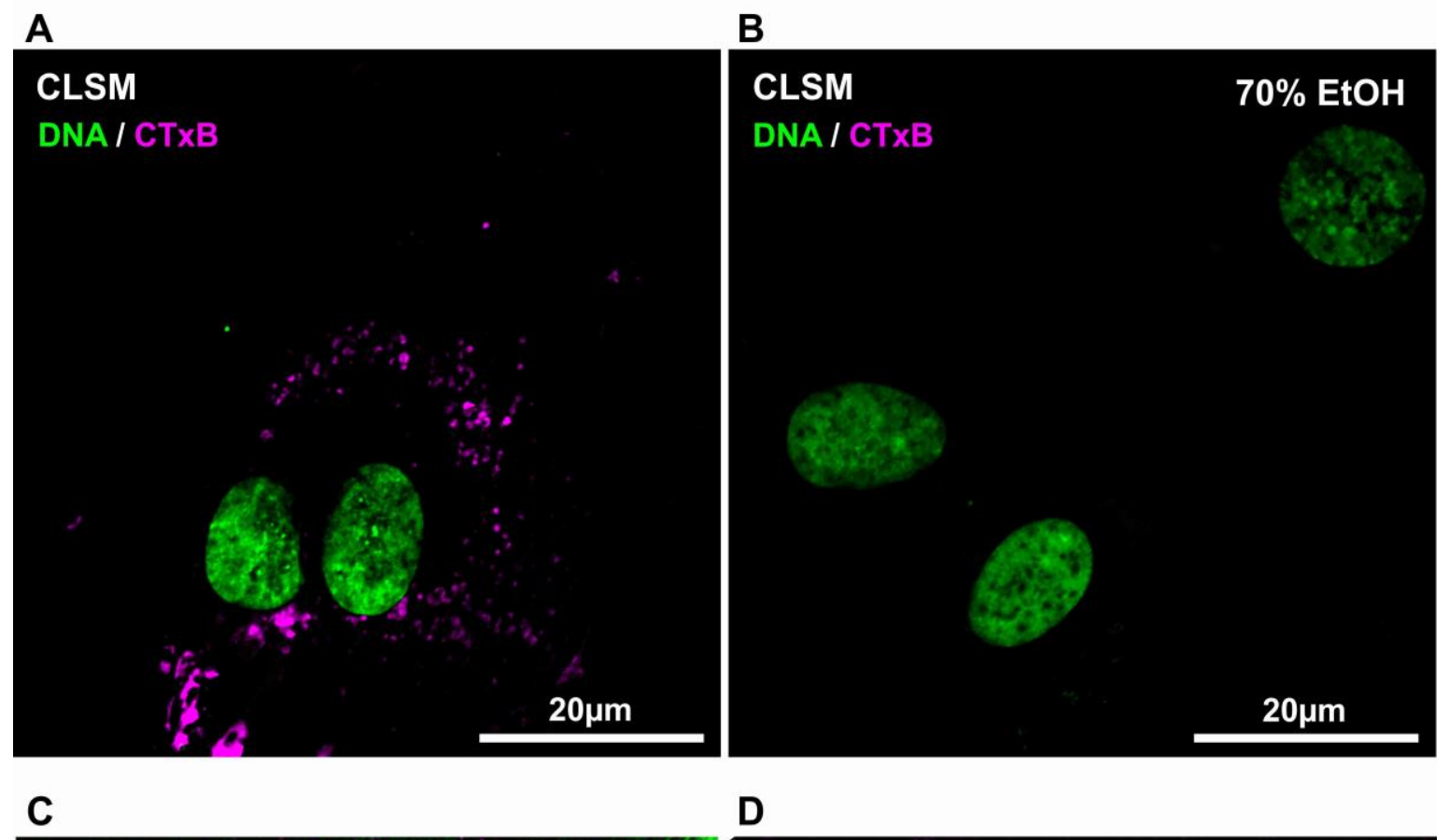

B

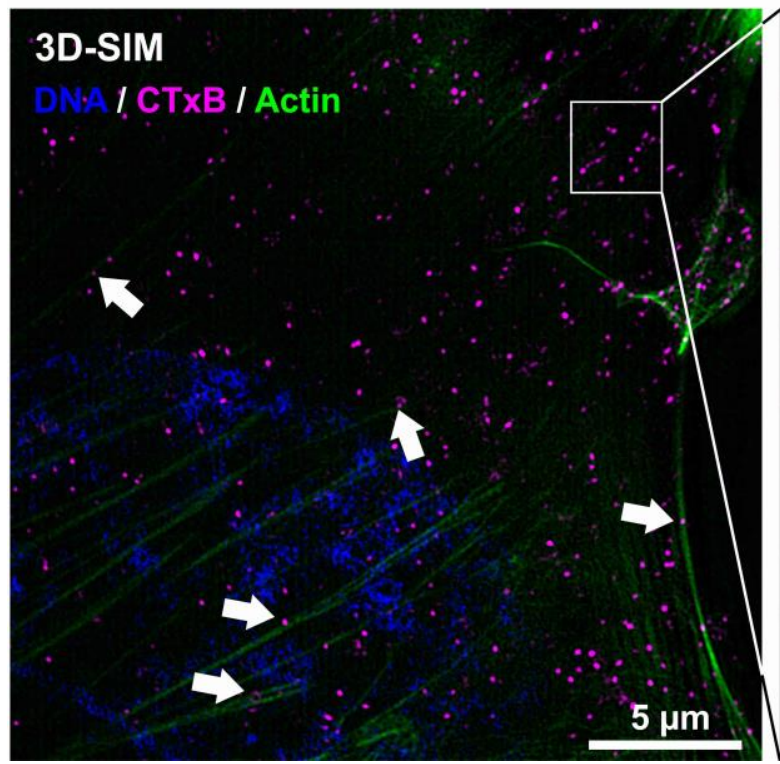

dSTORM

$\mathrm{CTXB}$

$1 \mu \mathrm{m}$

Fig. 4. The domains in a fixed cell membrane positive for cholera toxin subunit $B$ (CTXB) can be extracted with ethanol suggesting a lipid raft-like and/or caveolae-nature. Confocal Laser Scanning Microscopy (CLSM) images of cells fixed with aldehydes and $\mathrm{OsO}_{4}$ were treated with ethanol (B) or remained in PBS (A) and subsequently stained with CTXB. The cells treated with ethanol show no positive signal for CTXB. 3D structured illumination microscopy (3D-SIM) (C) and direct stochastic optical reconstruction microscopy (dSTORM) (D) yielded images with a higher resolution. A homogenous but anisotropic distribution of CTXB positive membrane 
nanodomains is found. In addition, co-localization of nanodomains and actin filaments is marked by arrows (C). 


\section{Figure 5}

A
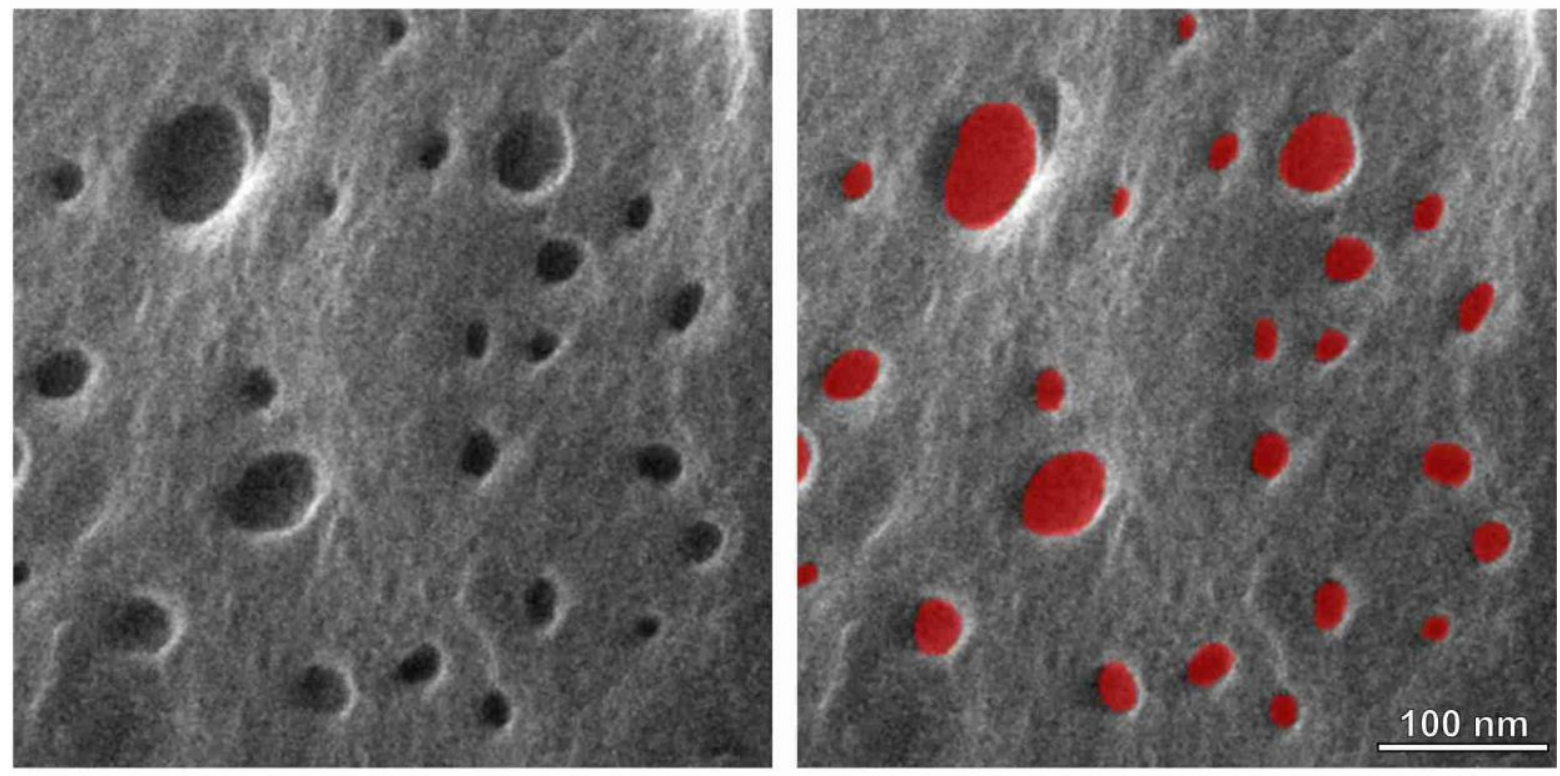

B

C
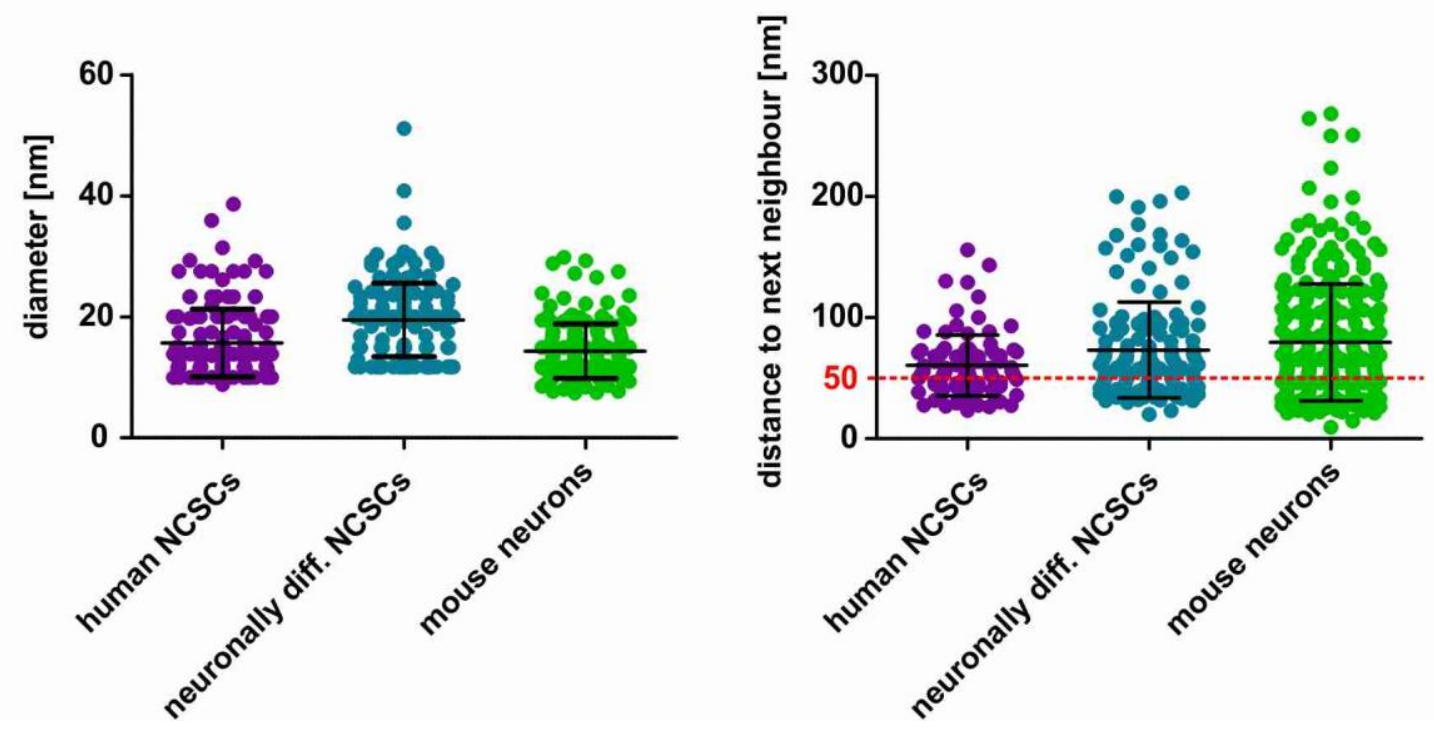

Fig. 5. Measurement of the size and distribution of membrane pits with nm-accuracy by HIM. (A) For measuring the properties of the pit like structures (lipid-nano-domains) the corresponding regions were marked in the HIM image of a NCSC derived human neuron soma. (B) The resulting size was measured at the soma for three different cell types (two cells per type). The size distributions of cells from the same type were comparable. The mean diameter for all investigated cell types was shown to be $\leq 20 \mathrm{~nm}$. (C) Further measurements regarding the distance to the next neighboring domain showed that a main fraction of the domains lies closer than $50 \mathrm{~nm}$ to it next neighbor and hence be at least partly of raft-like origin. 


\title{
SUPPORTING INFORMATION
}

\section{Helium Ion Microscopy visualizes Lipid Nanodomains in Mammalian Cells}

\author{
Matthias Schürmann ${ }^{1, *}$, Natalie Frese ${ }^{2,}$, André Beyer², Peter Heimann ${ }^{1}$, Darius Widera ${ }^{1,3}$, \\ Viola Mönkemöller², Thomas Huser², Barbara Kaltschmidt ${ }^{1}$, \\ Christian Kaltschmidt ${ }^{1, *}$, Armin Gölzhäuser ${ }^{2, \S, ~ * ~}$ \\ ${ }^{1}$ Faculty of Biology, Bielefeld University, 33501 Bielefeld, Germany \\ ${ }^{2}$ Faculty of Physics, Bielefeld University, 33501 Bielefeld, Germany \\ ${ }^{3}$ Reading School of Pharmacy, University of Reading, Reading, United Kingdom \\ *authors contributed equally \\ §corresponding author: ag@uni-bielefeld.de
}

Keywords: Helium Ion Microscopy, Bioimaging, Lipid Nanodomains, Lipid Rafts, Atomic Force Microscopy 
High resolution HIM imaging of neuronally differentiated NCSC revealed less pit like structures on the membrane of neurites in comparison to the somatic cell membrane.

\section{Supplementary Figure 1}

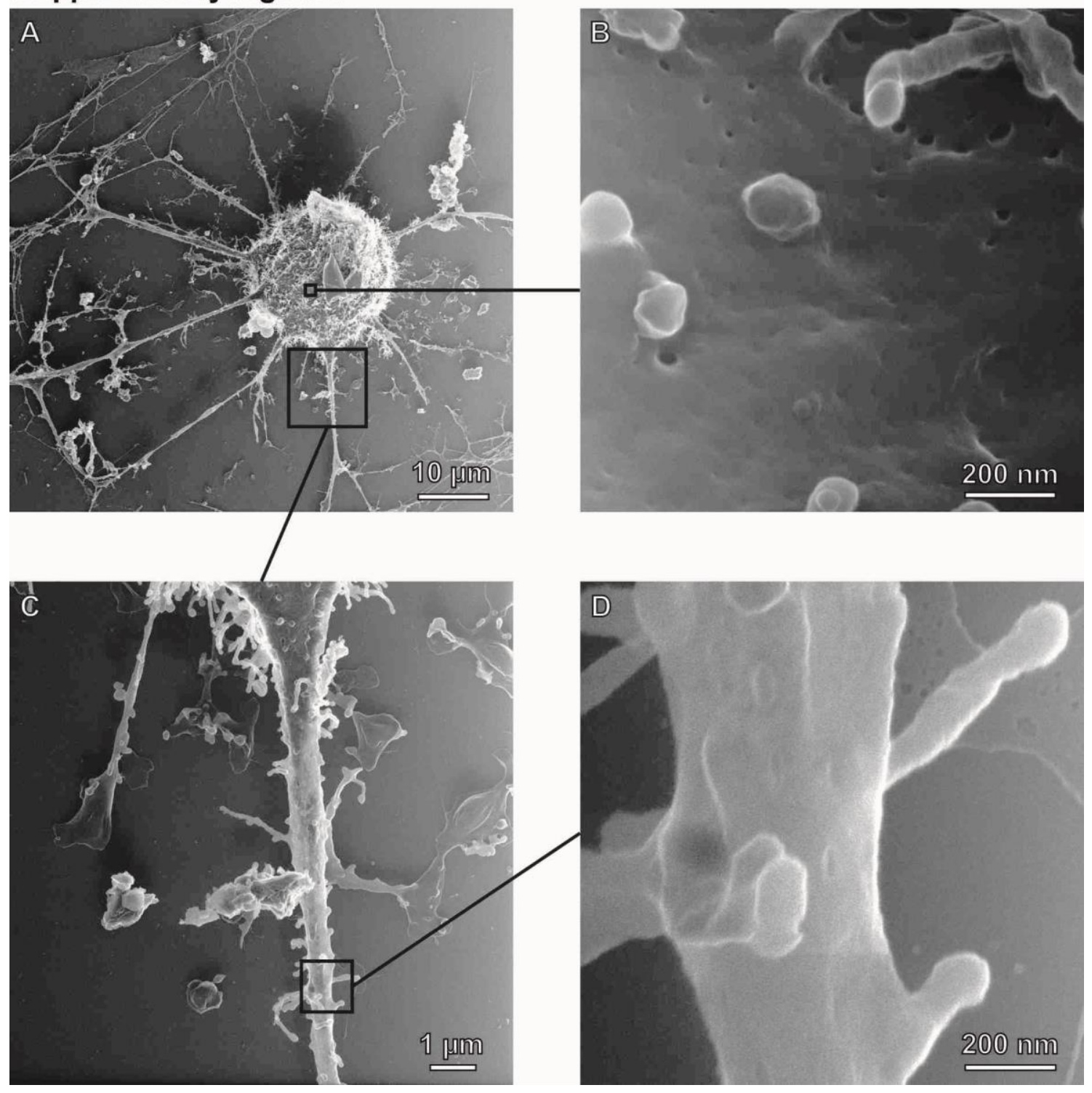

SI Fig. 1: Less membrane nanodomains in neurites as compared to soma. (A) HIM imaging was performed on NCSC differentiated towards the neuronal lineage. (B) Higher magnification of the somatic membrane shows pit-like nanodomains. (C) A neurite at higher magnification. (B, D) Highest magnifications of the somatic membrane and the membrane of the neurite indicate a higher density of nanodomains on the somatic membrane. 
High resolution HIM images of neuronally differentiated NCSCs revealed membrane domains of varying diameters (arrows) and shallow membrane indentations. Tilting of the sample clearly demonstrated that the observed membrane domains are of pit-like nature.

\section{Supplementary Figure 2}

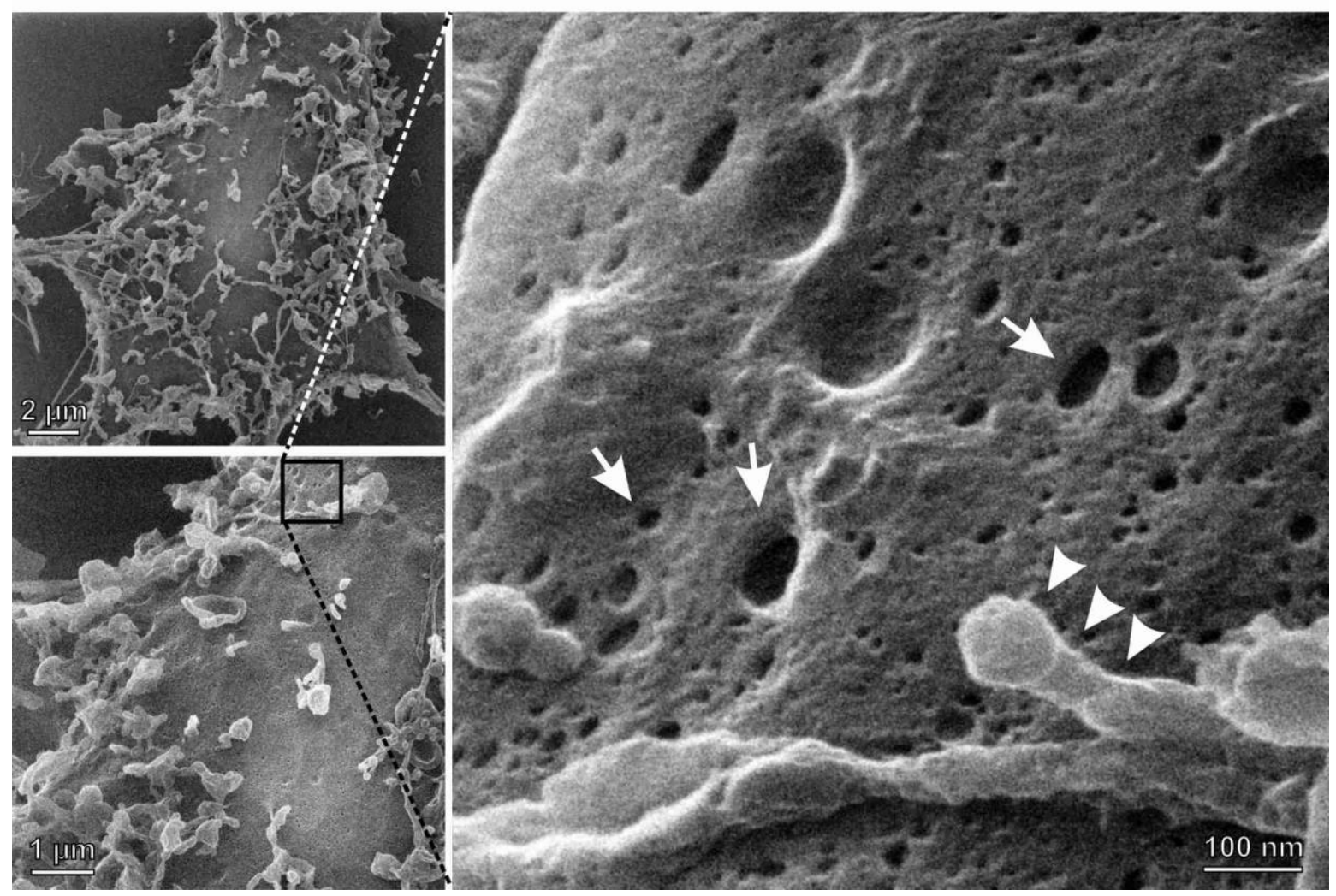

SI Fig. 2: Membrane nanodomains revealed by HIM are of pit-like nature. HIM imaging was performed on NCSC differentiated towards the neuronal lineage. By imaging a tilt region of the specimen and comparing the illumination of the edges of the membrane features (arrows) and on top laying particles (arrowheads) it becomes obvious, that the features are of pit-like nature and not surface protrusions. 
Neuronally differentiated NCSCs were also prepared for HIM by freeze drying which does not require treatment of the specimen with Ethanol or any other nonpolar solvent. At high magnification these samples showed the same features of the cell membrane with similar size and shape.

\section{Supplementary Figure 3}
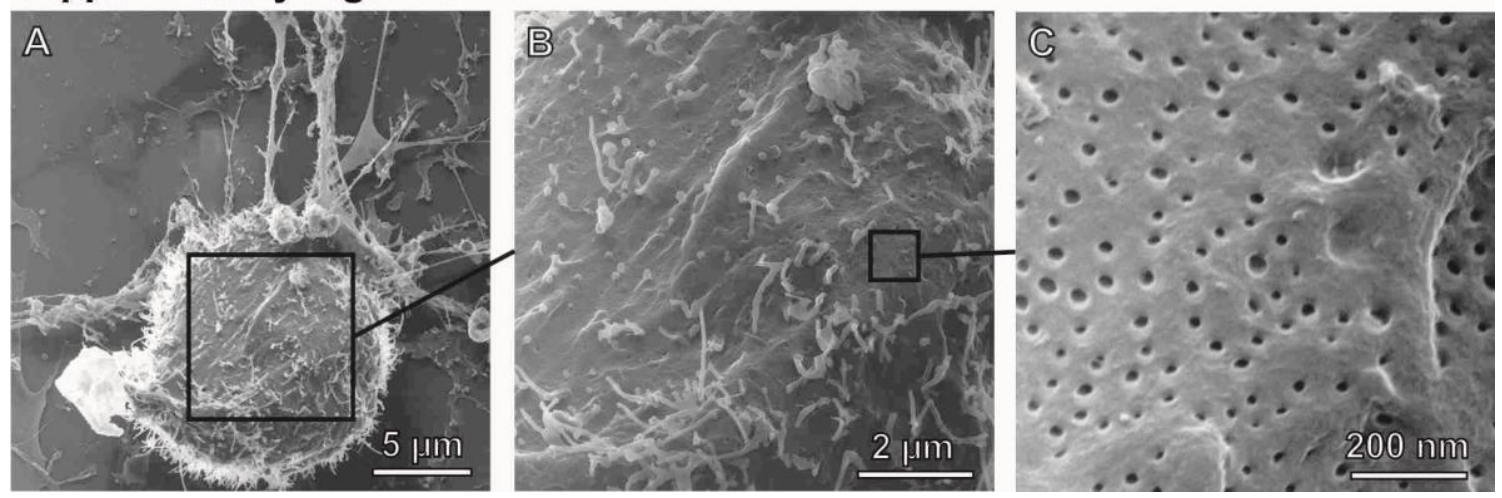

SI Fig. 3: Membrane nanodomains can be detected not only after critical point drying but also after freeze drying. (A) HIM imaging was performed on shock frozen freeze dried NCSC differentiated towards the neuronal lineage. (B) Higher magnification of the cell soma. (C) At highest magnification the nanodomains show similar size and shape as the nanodomains observed in critical point dried cell membranes. 
In general, HIM imaging is characterized by a resolution significantly superior to SEM. In our study, determination of the obtained edge resolution is based on ten subsequent line scans across a sharp edge in a HIM image. The edge resolution of each individual line scan was determined and the average was calculated. It has a value of $1.5 \mathrm{~nm}$ with a standard deviation of $0.9 \mathrm{~nm}$ (see Supplementary Fig. $4 \mathrm{~A}$ ). In dSTORM, an important quantity which is related to the resolution is the localization precision. This value describes the position uncertainty of each detected fluorophore and it has a typical value of around $15 \mathrm{~nm}$ (see Supplementary Fig. 4 B).

\section{Supplementary Figure 4}
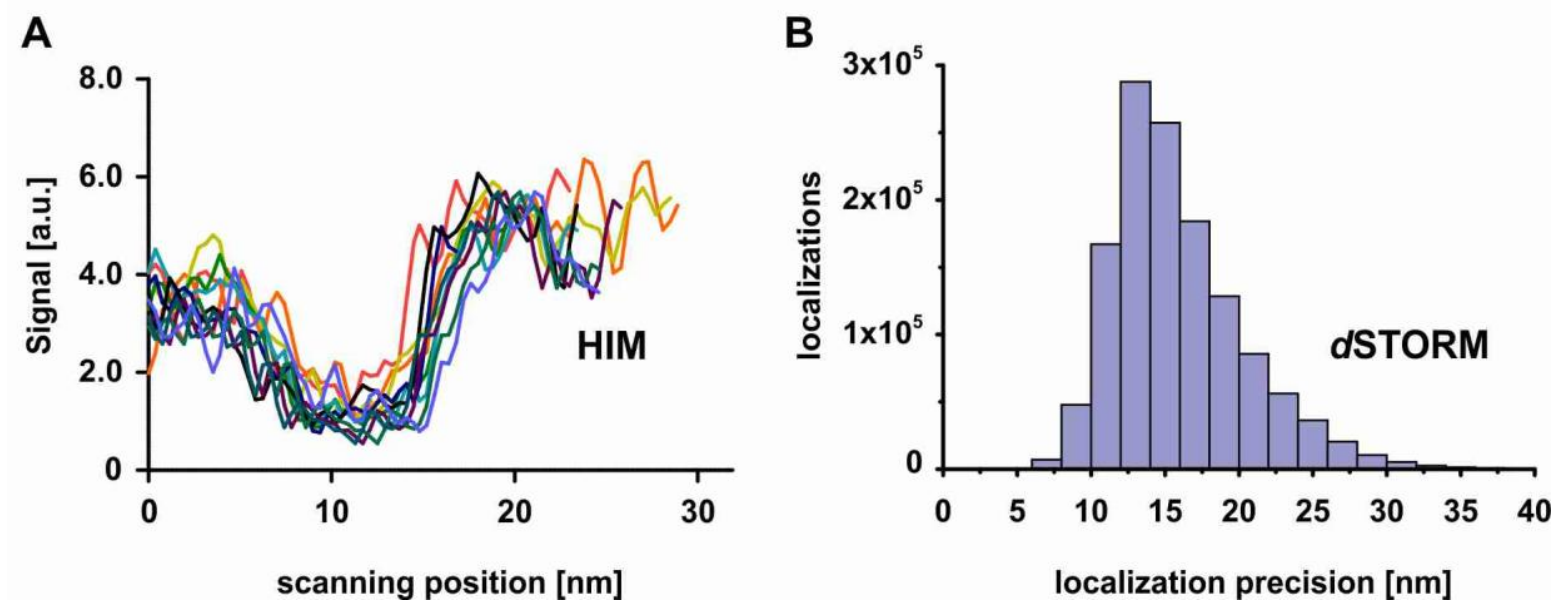

SI Fig. 4: Characteristics of HIM and dSTORM. (A) Line scans in a HIM image across a pitlike feature revealing an edge resolution of $1.5 \mathrm{~nm}$ with a standard deviation of $0.9 \mathrm{~nm}$ (see Methods). (B) Distribution of the obtained localization precision values in ISTORM. The localization precision was calculated for each detected fluorophore in rapidSTORM. 
The detected nanodomains in the dSTORM image in Fig. $4 D$ appear to be slightly larger in comparison to the pit like structures (lipid-nano-domains) found by HIM. This is quantified by the size distribution of nanodomains in dSTORM in Supplementary Fig. 5. The mean diameter is clearly larger than $20 \mathrm{~nm}$ which is found as an upper limit for the mean diameter of different cell types in HIM. Part of this seeming discrepancy is explained by the localization precision in dSTORM of about $15 \mathrm{~nm}$ (see Supplementary Fig. 4 B). Thus, even labeled nanodomains with a size of less than $15 \mathrm{~nm}$ will appear in dSTORM exhibiting a size of at least $15 \mathrm{~nm}$. In addition, very small nanodomains are not very efficiently labeled, i.e. the probability of label attachment becomes very small for small nanodomains. This can be easily seen by comparing the density of nanodomains in the dSTORM image in Fig. $4 D$ with the much higher density of pit like structures in the HIM image in Fig. 5 A. Thus, only a very small fraction of small nanodomains is detected while a very high fraction of large domains is imaged by dSTORM. This explains the shift of the apparent mean diameter to larger values for dSTORM.

\section{Supplementary Figure 5}

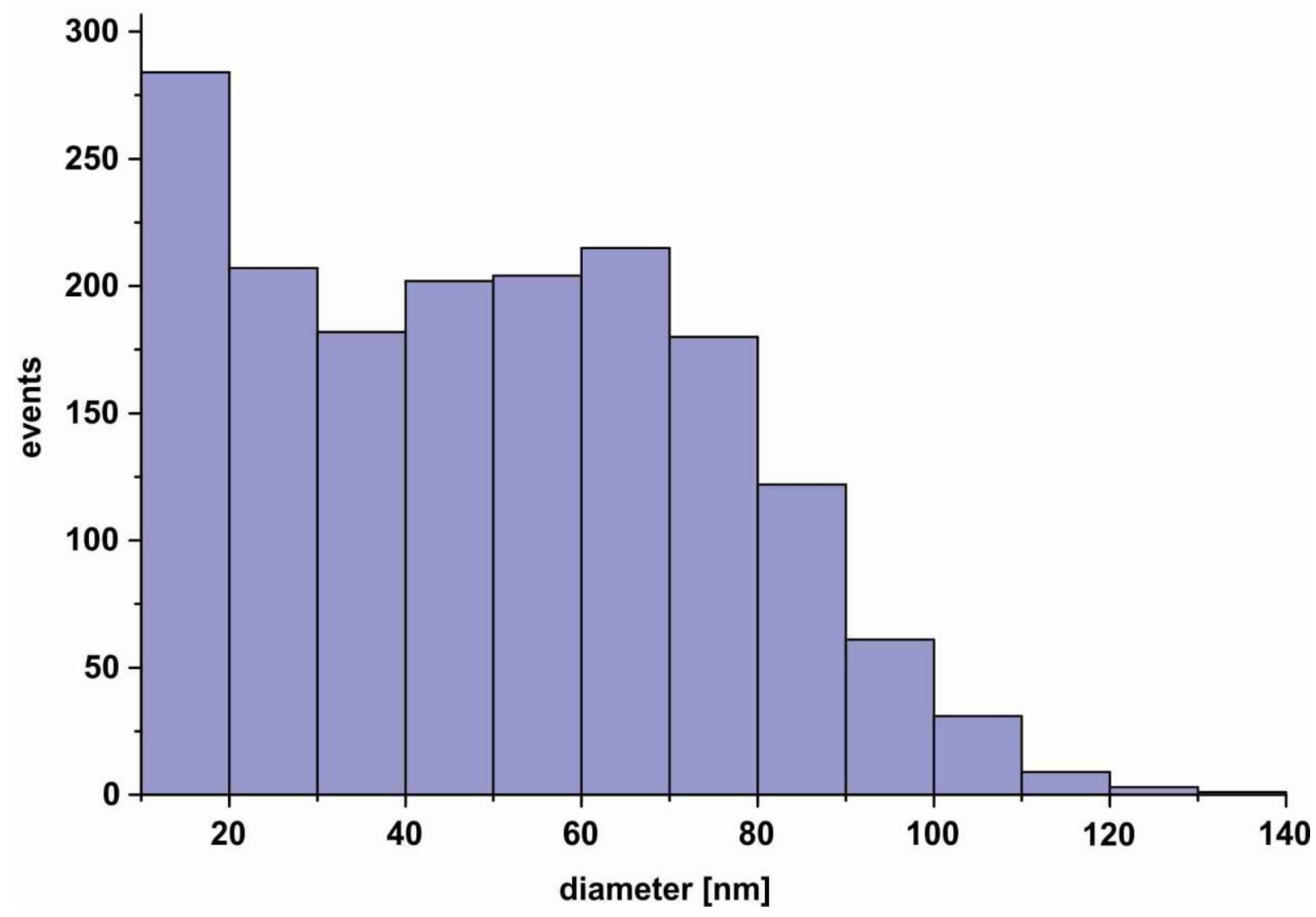

SI Fig 5: Size distribution of CTXB labeled membrane nanodomains quantified by dSTORM. This size distribution is compatible with the size distribution of pit like structures (lipid- 
nano-domains) found by HIM (cf. Fig. 5 B) if the localization precision and the labeling process is taken into account. 
Analyzing the morphological appearance of caveolae elucidates the steric hindrance between two caveolae when they approach to each other.

\section{Supplementary Figure 6}

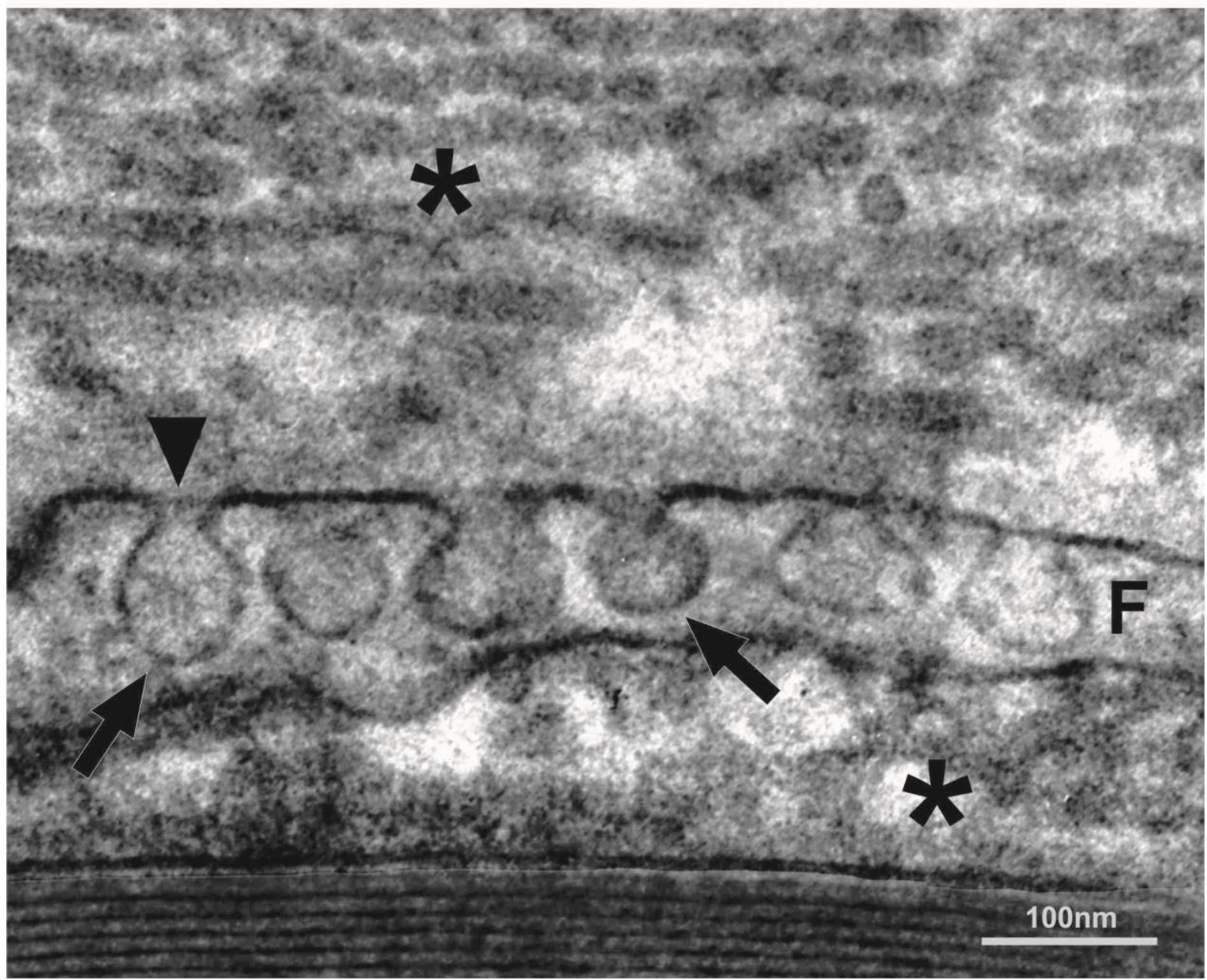

\section{SI Fig 6: Fine structure of caveolae in a fibroblast by transmission electron microscopy.} The fibroblast $(F)$, surrounded by extracellular matrix (asterix), shows numerous caveolae (arrows) including their opening (arrowheads) to the extracellular space in the cell membrane during endocytosis. The size of the caveolae prevents that the distances between openings are less than $50 \mathrm{~nm}$. 